\title{
Das Schicksal der bayerischen Kriegsgefangenen in Rußland 1812 bis 1814
}

Der bayerische Anteil am russischen Feldzug Napoleons im Jahre 1812 ist in weiten Teilen von der historischen Forschung untersucht worden - naturgemäß jedoch unter dem Blickwinkel der klassischen Kriegsgeschichte. Kaum Beachtung hingegen fand die Frage nach dem Schicksal jener Soldaten, die in russische Kriegsgefangenschaft geraten waren. Ihre Zahl läßt sich leider nicht mehr ermitteln, sie dürfte aber schätzungsweise mehrere Tausend umfaßt haben ${ }^{1}$. Zur einhundertjährigen Wiederkehr des Feldzugs nahm sich der Historiker Paul Holzhausen ${ }^{2}$ im Jahre 1912 dieses Problems zwar an, doch er verarbeitete die dazu von ihm herangezogenen Tagebücher und Memoiren bayerischer Teilnehmer an diesem Krieg zu einseitig im nationalistischen Tenor der Zeit, nur darauf bedacht, die unbestreitbar grausame, aber in dieser Intensität temporäre russische Gefangenenbehandlung hervorzuheben. Eine Durchsicht dieser Memoirenliteratur zeigt aber, daß die bayerischen Kriegsgefangenen in Rußland keineswegs als Freiwild angesehen und dementsprechend behandelt wurden.

Darüberhinaus geben die im Bayerischen Hauptstaatsarchiv München, Abt. IV Kriegsarchiv, verwahrten Akten zum Rußlandfeldzug Einblicke in bisher ebenfalls unberücksichtigte Bereiche wie beispielsweise die von Staats wegen gemachten Anstrengungen zur Repatriierung der Gefangenen und zur Klärung der Vermißtenschicksale. Von der Forschung weitgehend unbeachtet blieb auch das Verhalten der bayerischen Behörden gegenüber jenen Soldaten, die im Zustand der Kriegsgefangenschaft zur "RussischDeutschen Legion « übergetreten waren ${ }^{3}$.

\section{Die Bayern in der russischen Kriegsgefangenschaft}

Der Akt der Gefangennahme, sei es in Gefechten, Lazaretten oder während des Rückzugs, war nahezu ausnahmslos - sowohl bei den Offizieren als auch bei den Mannschaften - von Mißhandlungen und Plünderungen begleitet ${ }^{4}$, ausgenommen bei Generalmajor Graf v. Preysing-Moos, dem Führer der bayerischen Kavalleriedivision bei der "Grande Armée«. Mit ausgesuchter Höflichkeit wurde jener von den russischen Generalen empfangen, und am 7. Dezember 1812 kam es sogar zu einer Unterredung mit dem russischen Oberkommandierenden Kutuzov, der ihm sogleich 500 Rubel zu seiner Verfügung aushändigte. Außerdem gestattete Kutuzov ihm, brieflich Kontakt mit General Karl Philipp v. Wrede, dem Kommandeur des bayerischen Kontingents in der Armee Napoleons, sowie mit der Familie Preysing aufzunehmen. Nach Preysings Memoiren wies ihm Kutuzov dann als besondere Ausnahme die Stadt Jaroslavl an der oberen Volga als Aufenthaltsort $\mathrm{zu}^{5}$.

Allen bayerischen Gefangenen gemeinsam war jedoch der Wegtransport in das Innere des russischen Reiches. Holzhausen legte diesem Vorgang drei hauptsächliche Motive zugrunde:

1. Rußland rechnete mit einem erneuten Einfall Napoleons. In diesem Fall sollte die zu erwartende Kampfzone von Gefangenen möglichst frei sein.

2. Den Kriegsgefangenen sollte die Größe Rußlands vor Augen geführt werden, damit sie nach ihrer Rückkehr in die Heimat von der Weite und der Macht des Zarenreiches berichten konnten.

3. Die russischen Behörden wollten durch das jämmerliche Aussehen der Gefangenen die Taten der eigenen Armee glorifizieren. 
Ohne seine Behauptungen im einzelnen zu belegen, führte Holzhausen diese Verschikkung auf einen schriftlichen Befehl der russischen Regierung zurück ${ }^{6}$. Tatsächlich aber plante Zar Alexander I., alle deutschen Gefangenen von den Franzosen zu trennen, sie nach Reval (heute russisch Tallin) transportieren zu lassen, um sie dort für die "Russisch-Deutsche Legion" anzuwerben und im Kampf gegen Napoleon einzusetzen. Diesbezügliche Befehle sollen auch vom russischen Kriegsministerium ergangen sein, doch sah die Realität ganz anders aus. Gleich den Franzosen wurden auch die Deutschen in das Innere Rußlands getrieben ${ }^{7}$. Die Nichtbefolgung des kaiserlichen Willens mag in der Ablehnung der russischen Verwaltung gegen alles Deutsche begründet gewesen $\operatorname{sein}^{8}$. So hatte man gar kein Interesse, die nicht-französischen Kriegsgefangenen bevorzugt zu behandeln. Darüber hinaus schien sowohl manchem russischen Soldaten als auch Offizier der Unterschied zwischen einem Franzosen und einem Deutschen oder gar einem Bayern überhaupt nicht klar gewesen zu sein. Mit den Worten "gib Geld Franzuß« wurde beispielsweise ein bayerischer Sergeant seiner Ersparnisse beraubt ${ }^{9}$. Im Inneren Rußlands begrüßte ein russischer Kommandant einen deutschen Offizier mit »Franzuß, Schelma «" ${ }^{10}$.

Neben dem willkürlichen Verhalten der russischen Verwaltung sowie der Unkenntnis der Soldaten deutet aber trotzdem manches auf Transportbefehle aus dem russischen Hauptquartier hin. Nach der Niederlage der alliierten Truppen bei Bautzen und Lützen im Mai 1813 erhielt der Gouverneur von Vilna die Ordre, die Stadt von allen Gefangenen zu räumen und sie in weiter östliche Gebiete zu verbringen ${ }^{11}$.

Für viele Gefangene wurde der Marsch in das Landesinnere unter schlimmsten Bedingungen eine Reise in den Tod; aus welchen Gründen auch immer er angetreten werden mußte. Äußerst karge Verpflegung - manche Kolonnen erhielten nur alle fünf Tage etwas gedörrtes Brot und dabei oftmals nur einen kleinen Laib für mehrere Personen ${ }^{12}$ - und Mißhandlungen der Bewacher kosteten manchem das Leben ${ }^{13}$. Holzhausen führte einen Teil der Sterbefälle auf ein systematisches Verhungernlassen durch die russischen Bewacher zurück, die sich die für die Gefangenenverpflegung vorgesehenen Gelder in die eigene Tasche gesteckt haben sollen. Auch seien die Kriegsgefangenen der Wut der Bevölkerung schutzlos ausgeliefert gewesen ${ }^{14}$. Letzteres mag mit ein Grund für zahlreiche Todesfälle gewesen sein, zumal dann, wenn man sich das Verhalten der "Grande Armée " gegenüber den russischen Gefangenen vor Augen hält. Im November 1812 sollten auf ausdrücklichen Befehl Napoleons alle gefangenen Russen getötet werden, damit sie bei ihrer Befreiung nicht den wahren Zustand der Rheinbund-Armee verraten könnten ${ }^{15}$.

Die überwiegende Mehrheit der gesundheitlich sehr angeschlagenen bayerischen Kriegsgefangenen - schon seit dem Vormarsch im Sommer 1812 grassierten mangels ausreichender Verpflegung, Bekleidung sowie wegen des schlechten Wetters epidemische Krankheiten im Heer ${ }^{16}$ - dürfte aber aufgrund des katastrophalen Nahrungsmittelmangels in den vom Krieg verheerten Gegenden zugrunde gegangen sein. Selbst die russischen Wachmannschaften litten nach Auskunft eines kriegsgefangenen bayerischen Offiziers unter der kargen Verpflegung ${ }^{17}$. Das extreme Klima des russischen Winters - zu Beginn des Dezembers sanken die Temperaturen auf minus $30 \mathrm{Grad}$ nach Réaumur ${ }^{18}$ - verschlimmerte die Situation noch zusehends.

Neben all den Schrecklichkeiten in der Anfangsphase der Gefangenentransporte nach Osten darf aber nicht übersehen werden, daß sich die Zustände im Laufe der Zeit merklich besserten. Nach dem Bericht des bayerischen Oberleutnants v. Furtenbach erhielten die Gefangenen im Januar 1813 auf kaiserlichen Befehl vor ihrem Weitermarsch in Vilna Winterbekleidung aus eroberten französischen Magazinen ausgehändigt. Zusehends normalisierte sich auch die Verpflegungslage - zum einen durch die weitere Entfernung der Transporte von den verwüsteten Gebieten der Kampfzone, 
zum anderen durch die den Gefangenen zustehende und auch ausbezahlte Löhnung. Mit letzterer konnten durch Einkäufe bei Bauern oder Händlern die Lebensmittelrationen aufgebessert werden ${ }^{19}$. Machten die Kolonnen bei Adelssitzen Halt, so kam es nicht selten vor, daß die kriegsgefangenen Offiziere von den Besitzern bewirtet wurden ${ }^{20}$. Je weiter sich die Transporte aus den umkämpften Gebieten entfernten, desto weniger mühevoll scheint der Marsch gewesen zu sein, wurden doch für Offiziere teilweise sogar Wagen oder Schlitten bereitgestellt. „Es war überhaupt ein lustiger Transport, abwechselnd wurde gesungen « - so die Worte in Oberleutnant Furtenbachs Tagebuch ${ }^{21}$.

Nach wochen- und monatelangen Märschen erreichten die Gefangenen dann ihre Verwahrungsorte. Man steckte sie jedoch nicht in eigens errichtete Kriegsgefangenenlager, sondern verteilte sie in kleinen Gruppen auf die Städte und Ortschaften der Gouvernements $^{22} .239$ namentlich von den russischen Behörden verzeichnete bayerische Offiziere und Soldaten blieben im westlichen Teil Rußlands bei Białystok interniert ${ }^{23}$. Dies zeigt, daß die Gefangenen nicht, wie von Holzhausen behauptet, willkürlich verschleppt wurden ${ }^{24}$, sondern daß die Verwahrung mehr oder weniger organisiert erfolgte. Im übrigen wurden die kriegsgefangenen Bayern im ganzen russischen Reich verstreut, von der Eismeerregion bis zu den Steppengebieten am Fuße des Kaukasus ${ }^{25}$.

Wie bereits im Zusammenhang mit den Gefangenentransporten erwähnt, trat nach den Übergriffen und Exzessen in der Anfangsphase eine Zeit der Beruhigung ein, und die russische Seite ergriff Maßnahmen, die das Los der Gefangenen verbesserten. Die erste Sorge galt den Verwundeten und Kranken in den Lazaretten der Kampfzone. Diese sogenannten Spitäler - zumeist Ställe oder Scheunen - waren wie zum Beispiel in Mogilev in der Regel heillos überbelegt und mit Exkrementen angefüllt. Eine medizinische Versorgung gab es aus Mangel an Ärzten und Medikamenten praktisch nicht. Allenfalls hielt ebenfalls krank zurückgebliebenes Sanitätspersonal der »Grand Armée« einen notdürftigen Pflegebetrieb aufrecht ${ }^{26}$. Von diesen unhaltbaren Zuständen soll der Zar, als er die Lazarette von Vilna und Polock besichtigte, derart betroffen gewesen sein, daß er seinen Adjutanten unverzüglich mit der Instandsetzung der Krankenanstalten beauftragte. Nach geraumer Zeit verbesserten sich auch die Zustände in den sogenannten Spitälern spürbar, zumal die russischen Behörden gefangengenommene bayerische Sanitätsdienstgrade zur Krankenversorgung einsetzten ${ }^{27}$.

Über diese humanitäre Hilfe hinaus wurde den bayerischen Gefangenen von der russischen Gewahrsamsmacht eine dem jeweiligen Rang angeglichene Löhnung ausbezahlt - wie es scheint, ebenfalls auf eine Anordnung des Zaren hin ${ }^{28}$. Dem General v. Preysing-Moos standen demnach täglich drei Rubel zu, jeder Stabsoffizier bekam pro Tag einen Papierrubel und jeder Subalternoffizier mußte sich mit einem halben Kupferrubel oder 50 Kopeken begnügen. Unteroffiziere erhielten täglich 15, die einfachen Soldaten 10 Kopeken. Ein halber Kupferrubel entsprach etwa 15 bayerischen Kreuzern. Wie den Erinnerungen zu entnehmen ist, wurden die Gelder auch regelmäßig ausgezahlt ${ }^{29}$. Unter dem Gesichtspunkt der Kaufkraft in Rußland läßt sich dabei feststellen, daß die materielle Situation jener Kriegsgefangener, die in den Genuß solcher Zahlungen gekommen waren, gar nicht so schlecht gewesen sein kann, waren die Nahrungsmittel, wie nachfolgende Aufstellung zeigt, doch relativ preisgünstig ${ }^{30}$.

1 Pfund Schweinefleisch $11 / 2$ Kreuzer

1 Pfund Hammelfleisch 1 Kreuzer

8 Pfund Brot $\quad 41 / 2$ Kreuzer

1 Pfund Butter 6 Kreuzer

1 Huhn $41 / 2$ Kreuzer 
Ein Hinweis auf das den Umständen entsprechende erträgliche Auskommen der Offiziere findet sich auch darin, daß Löhnungserhöhungen von einem halben auf einen ganzen Rubel Proteste und Neid bei der russischen Beamtenschaft hervorrief, so daß die Maßnahme wieder zurückgenommen werden mußte ${ }^{31}$. Den einfachen Soldaten stand zudem noch eine Naturalentlöhnung zu. Teilweise wurden auch freiwillige Arbeitsleistungen entgolten ${ }^{32}$. Von einem Arbeitszwang hingegen ist nichts bekannt.

Neben den Geldzahlungen durch die russischen Behörden bemühten sich auch Mitglieder der Zarenfamilie und des bayerischen Herrscherhauses um Unterstützung für die Gefangenen. Königin Karoline von Bayern, eine gebürtige Prinzessin von Baden, versuchte mit Hilfe ihrer Schwester Elisabeth, der Frau Zar Alexanders I., das Los der Bayern in Rußland zu lindern. Über eine gemeinsame Schwester, Prinzessin Amalie von Baden, wurde der Kontakt zwischen München und St. Petersburg hergestellt. Am 17. Januar 1813 konnte die bayerische Königin in einem Brief an ihre Mutter mitteilen, daß sie von Elisabeth beruhigende Nachrichten in der Kriegsgefangenenfrage erhalten habe $^{33}$. Wenige Tage später ist in einem weiteren Brief von einer Subskription zu lesen, zu der Zarin Elisabeth zugunsten der Gefangenen in Rußland aufgerufen hatte. Innerhalb von vier Wochen sollen dadurch 300000 Rubel an Unterstützung zusammengekommen sein ${ }^{34}$.

Zu den Bemühungen der Königin ließ König Max I. Joseph von Bayern am 10. Januar 1813 den bayerischen Hauptmann Baron v. Völderndorff als Parlamentär von Plock an der Weichsel in das Hauptquartier der russischen Westarmee zu General Čičakov entsenden, um jenem 900 Napoleondors zur Verteilung an die Gefangenen zu übermitteln. Allein ein Viertel der Summe war für den General v. Preysing-Moos bestimmt. Die Geldübergabe konnte erfolgreich abgewickelt werden. Völderndorff brachte bei seiner Rückkehr einen Brief General Čičakovs mit, worin die fürsorgliche Behandlung der bayerischen Kriegsgefangenen durch die russische Gewahrsamsmacht zugesichert wurde ${ }^{35}$. Wie ein Billet Max I. an den bayerischen Kriegsminister von Triva zeigt, wurde der Geldbetrag bei der Polizei in St. Petersburg deponiert. Von dort konnte er von den gefangenen Offizieren abgeholt werden ${ }^{36}$.

Bedeutsamer als die Maßnahmen des Königspaares dürfte für die Kriegsgefangenen jedoch der vom bayerischen Kriegsministerium organisierte Geldtransfer nach Rußland gewesen sein. Prinzessin Amalie von Baden, deren Vermittlung man sich dabei bediente, erhielt zu diesem Zweck von der Militärhauptkasse einen Kreditbrief in der Höhe von 1000 Louisdor an das St. Petersburger Bankhaus Livio zur Verfügung gestellt $^{37}$. Nach den Vorstellungen des Kriegsministeriums in München sollte die Auszahlung in Rußland durch die Prinzessin mit Hilfe eines gefangenen Offiziers vorgenommen werden. Dieser konnte jedem seiner Offizierskameraden eine Monatsgage aushändigen ${ }^{38}$. Amalie bestimmte hierzu den in St. Petersburg internierten Obersten v. Comeau, der von ihr bzw. dem Bankier Livio zwischen April und November 1813 zur Weiterleitung an die gefangenen Bayern 3211 Gulden 44 1/2 Kreuzer in Empfang nahm ${ }^{39}$. Nach der Rückkehr in Bayern wurden den Offizieren diese Gelder allerdings von der für die Zeit der Gefangenschaft nachbezahlten Gage wieder abgezogen ${ }^{40}$.

Mit Hilfe der badischen Prinzessin Amalie gelangten aber keineswegs nur Offiziere in den Genuß von Geldzuwendungen, sondern auch eine Reihe von Unteroffizieren und Soldaten. Ein "Verzeichniß über die durch den Banquier Livio zu St. Petersburg an K. B. Unteroffizier und Gem. bezahlten Gelder“ weist nach, daß zwischen dem 29. Juli 1813 und dem 20. Februar 1814 die Summe von 4178 Rubel ausbezahlt worden war. Einem Chirurgischen Praktikanten standen demnach einmalig 60 Rubel zu, ein Sergeant mußte sich mit sieben Rubel begnügen ${ }^{41}$. 
Memoiren werden diese Zahlungen genannt ${ }^{42}$, in anderen findet sich nichts darüber. Nach einem Verzeichnis des Obersten Comeau wurden von ihm 80 Quittungen ausgestellt, doch empfing nicht selten ein Offizier eine größere Menge Geld für seine Kameraden mit ${ }^{43}$. Der Liste des Bankhauses Livio ist zu entnehmen, daß etwa 250 Unteroffiziere und Soldaten Zuwendungen erhalten haben ${ }^{44}$. Auch alle in der Gegend von Polock an der Düna (russisch: Dvina) internierten bayerischen Offiziere wurden von der Prinzessin Amalie unterstützt ${ }^{45}$.

Aufgrund dieser vielfältigen Hilfsaktionen konnten in der Regel die kriegsgefangenen Offiziere ein den Umständen entsprechend sorgenfreies Leben führen. Da keine Arbeitsverpflichtung bestand, vertrieb man sich die Zeit zum Beispiel mit der Herstellung von Schattenrissen oder der Anfertigung von Zeichnungen, man pflegte die Gesellschaft untereinander sowie mit russischen Adeligen, denen sich mit den von weit her kommenden Gefangenen eine angenehme Abwechslung bot. Manch bayerischer Offizier wurde von seinen russischen Bekannten sogar auf Reisen im Zarenreich mitgenommen ${ }^{46}$.

Diese relativ angenehmen materiellen Lebensbedingungen einer kleinen Gruppe von Privilegierten dürfen aber keineswegs darüber hinwegtäuschen, daß es der Mehrheit der gefangenen Bayern - insbesondere den einfachen Soldaten - vermutlich nicht annähernd so gut ging. Für sie stand die tägliche Sorge um Nahrung im Mittelpunkt, hinzu kamen - wie wohl auch bei den Offizieren - Heimweh und die Angst, für lange Jahre im russischen Reich bleiben zu müssen. Die letzte Befürchtung entbehrte aber bereits im Herbst 1813 jeglicher Grundlage. Nach dem Übertritt Bayerns in das Lager der Alliierten - vollzogen am 8. Oktober 1813 mit der Unterzeichnung des Vertrags von Ried ${ }^{47}$ - wurde Generalmajor Johann Baptist v. Verger am 24. Oktober beauftragt, die Interessen des bayerischen Königs bei den verbündeten Mächten zu vertreten. Ausdrücklich schrieb ihm seine Instruktion dabei vor, sich für die Rückführung jener bayerischen Soldaten einzusetzen, die während des russischen Feldzugs sowie im Verlauf des Rückzuges in den Städten Thorn und Danzig in Gefangenschaft geraten waren ${ }^{48}$. Nach kurzen Verhandlungen mit dem russischen Gesandten am alliierten Hauptquartier, Graf Nesselrode, konnte Verger am 18. November 1813 dem Staatsministerium der Armee in München mitteilen, daß die russische Regierung beabsichtige, alle in Rußland internierten bayerischen Soldaten unverzüglich zu entlassen und nach Warschau zu transportieren. Dort könnten sie von einem Kommissär in Empfang genommen und nach Bayern weitergeleitet werden ${ }^{49}$. Überraschenderweise entschied sich die russische Seite plötzlich für die drei Übergabeorte Riga, Radzivilov und BrestLitovsk ${ }^{50}$; das bayerische Kriegsministerium bestimmte die Obersten v. Gumppenberg und Bernclau sowie den Major v. Fürstenwärther als Übernahmekommissäre ${ }^{51}$. Offensichtlich aufgrund des nachdrücklichen Drängens von Verger änderten die russischen Behörden ihren Plan erneut und erklärten sich bereit, alle bayerischen Kriegsgefangenen auf Kosten des russischen Staates nach Warschau zu schaffen ${ }^{52}$.

Die Nachricht vom Übertritt Bayerns auf die Seite der Napoleon-Gegner sowie die Kunde von den siegreichen Schlachten bei Leipzig und Hanau weckten bei den Kriegsgefangenen Hoffnung auf baldige Heimkehr ${ }^{53}$. Im November 1813 kam dann der erlösende Ukas Zar Alexanders I. Alle in den Ortschaften verstreuten Bayern sollten in den jeweiligen Gouvernementsstädten versammelt und mit Winterbekleidung ausgestattet werden ${ }^{54}$. Anders als im Winter des Jahres zuvor reisten die Entlassenen nun unter weit angenehmeren Bedingungen, denn die russischen Behörden stellten Pässe, Schlitten oder Postwagen sowie Führer bereit ${ }^{55}$. Da manche Offiziere scheinbar über nicht unbeträchtliche Geldmittel verfügten, konnten sich einige Schlitten kaufen und damit Warschau schneller erreichen ${ }^{56}$. 
Während die Entlassenen dem Großherzogtum Warschau zustrebten, bereitete der bayerische Übernahmekommissär, Oberst Kajetan Frhr. v. Gumppenberg, die Aufnahme und den Rücktransport in die Heimat organisatorisch vor. Nach seinen Instruktionen vom 6. Januar 1814 hatte er zunächst mit der sächsischen und preußischen Regierung die Marschrouten der Heimkehrerkolonnen auf deren Gebiet sowie Fragen der Unterkunft und Verpflegung abzuklären. Für das eigentliche Übernahmegeschäft in Warschau ließ das Kriegsministerium Gumppenberg ziemlich freie Hand - lediglich in Fragen der Besoldung, der Ausrüstung und der Rückführung nach Bayern hatte man bereits vorab Anordnungen getroffen. Allen Offizieren und Militärbeamten sollte daher gleich bei der Ankunft in Warschau ein Vorschuß auf ihr während der Gefangenschaft angewachsenes Gagenguthaben in Höhe von drei Monatsgagen ausbezahlt werden. Unteroffizieren und Soldaten stand nichts Vergleichbares zu. Sie bezogen ihren Sold erst wieder mit dem Eintreffen in Warschau. Da man bei den Entlassenen auch eine unzureichende Bekleidungsausstattung vermutete, war der bayerische Kommissär gehalten, zur kostenlosen Ausgabe an die Bedürftigen eine größere Anzahl Monturstücke bereitzuhalten. Offiziere mußten im Hinblick auf die Löhnungsnachzahlung selbst für die Anschaffung ihres Anzugs sorgen. Die Rückführung der entlassenen Kriegsgefangenen stellte sich das Kriegsministerium in Form mehrerer, von Offizieren befehligten Maschkolonnen vor. Als Auslaufpunkt dieser Transporte in Bayern war Bayreuth vorgesehen, wo die Kolonnen aufgelöst und die Soldaten ihren Heimatgarnisonen zugeführt werden sollten ${ }^{57}$.

Am 6. Februar 1814 traf Oberst v. Gumppenberg in Warschau ein, nachdem er im Verlauf seiner Reise die notwendigen Absprachen mit den sächsischen und preußischen Verwaltungsinstanzen getroffen hatte. Vom Generalgouverneur des Großherzogtums Warschau, Graf Lanskoij, wurde Gumppenberg die volle Unterstützung der russischen Behörden zugesichert ${ }^{58}$. Die persönliche Anteilnahme des Gouverneurs ging sogar so weit, daß er die zurückkehrenden Offiziere jeweils persönlich empfing ${ }^{59}$.

Nach wenigen Tagen Aufenthalt Gumppenbergs kam am 11. Februar 1814 der erste Heimkehrertrupp unter Führung eines Leutnants mit zwei Unteroffizieren und 39 Soldaten in Warschau an ${ }^{60}$. Bis zum 30. Juli 1814 riß der Zustrom der dem bayerischen Beauftragten übergebenen Gefangenen nicht mehr ab.

Den Aufenthalt für die entlassenen Kriegsgefangenen organisierte Gumppenberg zusammen mit seinem ebenfalls aus Heimkehrern zusammengestellten Hilfspersonal so, daß die oftmals sehr verdreckten Soldaten zunächst baden mußten und dann auf ihren Gesundheitszustand hin untersucht wurden. Wenn nötig, wurde dann warme Winterbekleidung ausgegeben ${ }^{61}$. Entsprechend den Befehlen des Kriegsministeriums erhielten die Offiziere ein Drittel ihres angewachsenen Gagenguthabens und die Soldaten einen dreimonatigen Löhnungsvorschuß ausbezahlt ${ }^{62}$. Nach wenigen Tagen Aufenthalt, in denen man die Soldaten durch tägliche Paraden wieder an das militärische Reglement gewöhnte, wurden, da man aus Gründen der Disziplin und aus finanziellen Erwägungen eine Zusammenballung zu vieler Heimkehrer in Warschau vermeiden wollte, in dreitägigem Abstand Marschkolonnen zusammengestellt. Da sich unter den Entlassenen aber erheblich mehr Offiziere befanden als zur Führung der Kolonnen notwendig waren, konnten die Überzähligen entweder auf eigene Rechnung mit regulären Postkutschen oder in Gruppen zwischen acht und zehn Personen unter kostenloser Gestellung von Wagen und Pässen schneller nach Hause reisen ${ }^{63}$. Die Strecke von Warschau über Breslau, Dresden oder Prag und Eger nach Bayreuth ließ sich auf diese Weise in knapp einem Monat zurücklegen ${ }^{64}$. Die Unteroffiziere und Soldaten hingegen kehrten zu Fuß nach Hause zurück. In täglichen Märschen zwischen sieben und acht Stunden benötigten sie doppelt so lange nach Bayreuth ${ }^{65}$. Die Verpflegung während des Heimmarsches stellte das russische Verpflegungsamt zur Verfügung, das je- 
dem Soldaten mehrere Bons aushändigte. Damit konnten bei den Ausgabestellen jeweils für sieben Tage 1 1/2 Pfund Fleisch, 21 Pfund Gerstengrütze und 1 1/16 Quart Branntwein in Empfang genommen werden ${ }^{66}$.

Zwischen dem 31. März und dem 27. Dezember 1814 passierten 24 Heimkehrerkolonnen in Bayreuth ein. Die Kommandantschaft meldete sowohl die Mannschaftstransporte als auch die allein oder in Gruppen reisenden Offiziere dem Generalkommando in Nürnberg, wobei man die Mannschaften nur summarisch, die Offiziere hingegen namentlich erfaßte. Eine Ausnahme hiervon ist der letzte Rapport vom 27. Dezember 1814, worin neben drei Offizieren auch die Namen von zwei Chirurgischen Praktikanten und zehn Soldaten verzeichnet sind ${ }^{67}$.

Am Ende seiner Mission in Warschau konnte Oberst v. Gumppenberg auf eine Heimkehrerbilanz von 153 Offizieren sowie 805 Unteroffizieren und Mannschaften zurückblicken, die ihm zwischen dem 4. Februar und 30. Juli von den russischen und auch preußischen Behörden, in deren Gewahrsam sich seit dem Frontwechsel Preußens im Dezember 1812 einige wenige Bayern befanden, übergeben worden waren. Lediglich zwei Soldaten waren nach der Entlassung aus der Kriegsgefangenschaft in Warschau verstorben. Den bayerischen Militärfiskus kostete die gesamte Aktion unter Einbeziehung der Gagennachzahlungen nach der Abrechnung Gumppenbergs 57500 Gulden ${ }^{68}$.

Wesentlich billiger - dafür aber auch in weit geringerem Umfang - gestalteten sich die Repatriierungsmaßnahmen durch den russischen Stadtkommandanten von Leipzig, Oberst Prendel. Bereits im Dezember 1813 hatten sich dort einige - vermutlich aus preußischer - Kriegsgefangenschaft entlassene Bayern eingefunden. Prendel nahm sich ihrer an und vermittelte sie zunächst an einen württembergischen Kommissär, der dort das Rückführungsgeschäft für seine kriegsgefangenen Landsleute übernommen hatte. In München war man über die Initiative des russischen Oberst hocherfreut und bat ihn daher, gegen Rückerstattung der verausgabten Gelder auch weiterhin heimkehrende Bayern zu unterstützen. Bis zum 1. Oktober 1814 half Prendel einer unbekannten Anzahl, ihre Heimat zu erreichen, indem er jedem 1 Gulden 40 Kreuzer und - bei Bedarf - ein Hemd oder ein Paar Schuhe aushändigen ließ ${ }^{69}$.

In ganz wenigen Fällen mußten sich auch 1814 die wiedereröffnete bayerische Gesandtschaft in St. Petersburg ${ }^{70}, 1816$ die Vertretung in Berlin ${ }^{71}$ und 1815 der bayerische Agent Gaddum im italienischen Triest mit der Unterstützung sowie Weiterleitung bayerischer Spätheimkehrer aus Rußland beschäftigen ${ }^{72}$.

Die Repatriierung der in russischer Gefangenschaft befindlichen Bayern war damit zwar abgeschlossen, nicht aber die Heimführung jener bayerischen Soldaten, die während des Feldzugs in die "Russisch-Deutsche Legion" desertiert oder im Zustand der Kriegsgefangenschaft dort Dienste genommen hatten.

\section{Bayerische Soldaten in der Russisch-Deutschen Legion}

Im Zusammenhang mit den Kriegsgefangenentransporten in das Innere Rußlands wurde bereits auf eine Anordnung Zar Alexanders I. hingewiesen, wonach alle deutsch-sprachigen Kriegsgefangenen der »Grande Armée« für die »RussischDeutsche Legion« angeworben werden sollten. Dieser Verband war im Sommer 1812 von deutschen Emigranten und russischen Offizieren gegründet worden, um Deserteuren der Rheinbundtruppen die Möglichkeit zum Kampf gegen Napoleon zu geben und somit zur Befreiung Deutschlands beizutragen ${ }^{73}$. Auch unter den bayerischen Truppen versuchte man, mit Hilfe von Flugzetteln Überläufer zu gewinnen. 
"Baiern! nicht genug, das Euch die Franzosen während des Feldzugs geopfert haben, erlauben sie euch sogar nicht in euer Land zurückzukehren. Baiern hört auf Sklawen Napoleons zu seyn. Die anderen Völker haben schon seine Ketten abgeworfen. Stehet auf, die Russen sind nicht euere Feinde; jeder Soldat der an ihre Vorposten kommt, erhält ein Billet hinzugehen wohin er will. Vermeidet das gewisse Verderbniß. In dem Billet wird man sagen, daß ihr von den Russen losgelassene Gefangene seyd, damit man euch nicht als Deserteure behandeln könne. " ${ }^{74}$

Der bayerische Major Ludwig Graf v. Seiboldsdorf, der diesen am 7. Februar 1813 in der Nähe der bayerischen Linien bei Plock an der Weichsel abgelegten Aufruf überliefert hat, meinte, er habe keinen Eindruck auf die Soldaten gemacht. Niemand sei desertiert.

Eine andere Werbemethode bestand darin, bereits übergelaufenen Offizieren in Zeitungsartikeln die Möglichkeit zu geben, Rechenschaft über ihren Eintritt in die »Russisch-Deutsche Legion« abzulegen sowie zur Nachahmung aufzufordern. Am 13. März 1813 erschien solch ein Artikel in der Königsberger Zeitung, der auch von mehreren bayerischen Offizieren mit unterzeichnet worden war.

"Wir Endes-Unterschriebene, aus Königl. Baierischen, Sächsischen, Westphälischen und Großherzoglich-Frankfurtischen Diensten zu der deutschen Legion übergetretene Offiziere, halten uns als Männer von Ehre verpflichtet, unseren Fürsten und dem $\mathrm{Va}$ terlande mit gebührender Ehrfurcht, Liebe und Vertrauen diejenigen Gründe öffentlich darzulegen, die zu diesem Schritte uns bewogen haben.

Wir sind Deutsche. In diesem einen Wort liegt schon alles. [. . .]

Wer jetzt noch gegen seine Brüder ficht, der ist in unseren Augen ein Vaterlandsverräther! wer nicht für sie fechten will, der verletzt seine heilige Pflicht! [ . .]

Wir sind überzeugt, daß selbst unsere verehrten Fürsten den von uns gethanen Schritt billigen werden, wenn gleich ihre Zungen jetzt noch gefesselt sind; wir sind überzeugt, daß wir ihren geheimen Wünschen zuvorkommen, indem wir für ihre eigene Selbständigkeit uns bewaffnen, und gäbe es einen unter ihnen der anders dächte, würde die Nachwelt ihn einen deutschen Fürsten nennen?

Uns hat keine persönliche Not unter die Fahnen der deutschen Legion geführt; uns leitet nur Ehrgefühl und Vaterlandsliebe. ${ }^{75}$

Inwieweit solche Maßnahmen Erfolg hatten, läßt sich schwer feststellen. Offensichtlich erfüllten sie ihren Zweck aber nicht, denn die Legion hatte bereits im Sommer 1812 ihren Rekrutierungsschwerpunkt auf die Werbung unter den Kriegsgefangenen verlagert $^{76}$. An Hand der bereits mehrfach erwähnten Feldzugsmemoiren stellten die Werber, die sowohl in unmittelbarer Nähe der Kampfzone als auch weit im Hinterland auftraten, die Gefangenen meist vor die Alternative, entweder eine gut besoldete Anstellung bei der "Russisch-Deutschen Legion« anzunehmen oder für immer nach Sibirien deportiert zu werden. Physischen Druck auszuüben gehörte dabei ebenso zum Repertoire wie eine baldige Entlassung in die Heimat nach dem Ende der Kampfhandlungen zu versprechen ${ }^{77}$. Die genaue Anzahl der so Gepreßten oder Überzeugten läßt sich bedauerlicherweise weder an Hand der Stärkerapporte der Legion ${ }^{78}$ noch mit Hilfe der im Bayerischen Kriegsarchiv verwahrten Akten ermitteln. Sicher ist nur, daß im September 1814 zwei Feldwebel, acht Sergeanten, zwei Spielleute und 166 Gemeine - alles ehemalige Angehörige des bayerischen Rußlandkontigents - aus der Legion entlassen wurden ${ }^{79}$. Eine größere Zahl ergibt sich an Hand des Vernehmungsprotokolls des bayerischen Legionssoldaten Ellmann. Nach dessen Schätzung sollen sich im Sommer 1814 etwa 300 Bayern in den Reihen der »Russisch-Deutschen-Legion« befunden haben ${ }^{80}$. Das Los dieser Leute scheint allerdings nicht das Beste gewesen zu sein, insbesondere dann, als der Verband unter preußisches Kommando gekommen war. Jetzt häuften sich die Klagen über die schlechte Behandlung durch die preußischen Unteroffiziere ${ }^{81}$.

Seit dem April 1813 waren die Behörden in München über den Dienst bayerischer Armeeangehöriger in der »Russisch-Deutschen Legion« unterrichtet. Das französische Außenministerium hatte dem bayerischen Ministerium des Äußeren und Königlichen 
Hauses eine Liste mit den Namen von 16 bayerischen, sächsischen, westfälischen und frankfurtischen Offizieren - eben jenen, die den oben erwähnten Aufruf in der Königsberger Zeitung unterschrieben hatten - übermittelt. Obwohl die französischen Stellen sehr auf eine Ahndung des Übertritts von fünf bayerischen Offizieren drangen, mußte man damit so lange warten, bis man ihrer habhaft werden konnte ${ }^{82}$.

Erst im Februar 1814 - mittlerweile stand Bayern seit mehreren Monaten auf seiten der Allianz gegen Napoleon - wurde der bayerische Vertreter am alliierten Hauptquartier, Baron Verger, beauftragt, bei der preußischen und russischen Regierung die Entlassung der in der Legion dienenden Bayern zu verlangen ${ }^{83}$. Nachdem dies durchgesetzt war, leitete Major Horn die Rückführung der Legionäre nach Bayern ein. Durch die Kriegslage war es zunächst schwierig, diesen Verband überhaupt ausfindig zu machen. Nicht gerade erleichtert wurde die Mission Horns auch durch das wenig kooperative Verhalten preußischer Militärstellen, die in Frage kommenden Leute überhaupt aus der "Russisch-Deutschen Legion« zu entlassen. Endlich, am 26. August 1814, konnte der bayerische Emissär 80 Infanteristen, 64 Kavalleristen und 47 Artilleristen in Marburg in Empfang nehmen und nach München eskortieren lassen. Von dort sollten sie wieder ihren alten Regimentern zugeführt werden. Im Verlauf dieses Transports zogen es aber nicht wenige vor, zu desertieren ${ }^{84}$. Mancher mag dabei befürchtet haben, für seinen Übertritt in Bayern gerichtlich belangt zu werden - eine unbegründete Angst, denn bereits am 28. Februar 1814 hatte König Max I. allen bayerischen Unteroffizieren und Soldaten der »Russisch-Deutschen Legion« Straffreiheit zugesichert.

»Wir haben hiermit befohlen, daß wegen Reklamation der in den Feldzügen von 1812 und 1813, in russisch oder preußische Kriegsgefangenschaft gerathenen, und zu den verschiedenen deutschen Legionen in rußisch oder preußische Dienste übergetretenen Militär Individuen, die geeignete Einleitung getroffen werde, und finden Uns nun, was die Behandlung dieser Individuen betrifft, in besonderer allergnädigsten Rücksicht noch zu beschließen bewogen, daß den Unteroffizieren und Soldaten, welche als Folge dieser Einleitung zurückkehren, wenn sie sich keines anderweitigen Vergehens schuldig gemacht haben, eine vollkommene Amnestie angedeihen solle. Dies wird Unserem Generalen der Kavalerie Grafen von Wrede zur Anweisung der einschlägigen Behörden allergnädigst eröffnet. ${ }^{85}$

Von diesem Gnadenakt ausgenommen waren jedoch die in der Legion dienenden bayerischen Offiziere, die wegen Desertion zum Feind der Strafverfolgung anheim fallen sollten. Nach Bekanntwerden dieser Absicht bei den Mitinitiatoren der "RussischDeutschen Legion« regte Frhr. vom Stein beim preußischen Minister Hardenberg an, Vorkehrungen zu treffen, wodurch die in Frage kommenden Personen in der Heimat nicht benachteiligt würden.

„Ew. Exz. beehre ich mich beikommend ein Schreiben des Obersten von Klewitz d. d. den 4. d. M. mitzuteilen, wonach die bayerische und württembergische Regierungen den Grundsatz annehmen, daß diejenigen Offiziere, welche früher ihre Dienste verlassen haben, um für die gemeinschaftliche Sache zu fechten, als Übertreter zu behandeln und von aller Anstellung auszuschließen seien. Die Würde der hohen verbündeten Souveräne und die rühmlichen Dienste, welche die Offiziere der Russisch-Deutschen Legion denselben geleistet haben, scheinen mir den Antrag wegen einer vorsorglichen Stipulation für diese braven Krieger hinreichend zu begründen und ich erlaube mir, deren Interessen Ew. Ex. gefälliger Berücksichtigung zu empfehlen. « ${ }^{86}$

Offensichtlich kam eine solche Vereinbarung aber nicht zustande, denn in Bayern stellte man diese Offiziere - ob sie nun freiwillig zurückgekehrt waren oder weiterhin abwesend blieben - auf ausdrücklichen Befehl des Königs unter Anklage ${ }^{87}$. Obwohl sie aufgrund des bayerischen Militärstrafgesetzes vom 16 . August $1813^{88}$ im schlimmsten Fall mit dem Tode bestraft hätten werden können, kamen die Beteiligten doch sehr glimpflich davon. 
Im Fall des freiwillig zurückgekehrten, um eine erneute Anstellung in der bayerischen Armee nachsuchenden Oberleutnants Karl Oswald v. Merkel erkannte das Kriegsgericht zwar auf Ausschluß aus der Armee, doch wurde diese Entscheidung per königlichem Gnadenakt ausgesetzt. Merkel konnte daraufhin wieder bei seinem alten Regiment eintreten. Mit ausschlaggebend für diese königliche Gunst mag auch gewesen sein, daß sich der Zar beim bayerischen König für diesen Offizier verwandt hatte ${ }^{89}$. Im ähnlich gelagerten Fall des Unterleutnants Max v. Thonus sprach das Gericht eine sechsmonatige Festungshaft aus, die der Verurteilte in Ermangelung von Fürsprechern, wie Merkel sie hatte, auch auf der Feste Oberhaus bei Passau absitzen mußte. Danach wurde aber auch er wieder bei seinem ehemaligen Regiment eingereiht ${ }^{90}$. In diesem Zusammenhang sind auch die Vorgänge um den bayerischen Korporal Zahner bemerkenswert, der es in der "Russisch-Deutschen Legion « bis zum Premier-Lieutenant und Regimentsquartiermeister gebracht hatte. Obwohl er im Sommer 1814 als Offizier nach Bayern zurückkehrte, war das Generalauditoriat der Auffassung, daß auch bei ihm die königliche Amnestie vom 28. Februar dieses Jahres gelten müsse, da er beim Übertritt in die Legion noch den Rang eines Unteroffiziers bekleidet hatte. Der König entschied in diesem Sinne. Zahner wurde unter Rückstufung auf seinen alten Korporalsdienstgrad wieder in der bayerischen Armee angestellt ${ }^{91}$. Diese Rangminderung war aber nicht von langer Dauer, beförderte man Zahner doch bereits im Februar 1815 zum Unterleutnant ${ }^{92} .1828$ avancierte er zum Oberleutnant und 1838 zum Rittmeister ${ }^{93}$. Darüber hinaus war ihm seit 1831 gestattet, sein russisches Adelsprädikat "von«, das er 1814 noch als Soldat der "Russisch-Deutschen Legion« durch die Verleihung des St. Vladimir-Ordens IV. Klasse, der in Rußland mit dem persönlichen Adel verbunden war, erlangt hatte, in Bayern zu tragen. Er hatte aber keinen Anspruch auf die Rechte des bayerischen Adels und die Immatrikulation in die Adelsmatrikel ${ }^{94}$.

Die nicht mehr nach Bayern zurückgekehrten Offiziere der "Russisch-Deutschen Legion« forderte das Generalauditoriat zunächst durch Aufrufe in Zeitungen auf, sich zu stellen und Rechenschaft über ihren Eintritt in fremde Kriegsdienste abzulegen. Andernfalls würden ihnen durch ein in Abwesenheit zusammentretendes Kriegsgericht die Offiziersstellen in der Armee aberkannt. Zur Deckung der Prozeßkosten sollte das Vermögen beschlagnahmt werden. Bei Ergreifung auf bayerischem Territorium drohte diesem Personenkreis zudem ein einjähriger enger Festungsarrest.

Nach Ablauf einer gewissen Frist wurden die in Abwesenheit der Beschuldigten gefällten Urteile rechtskräftig und sollten nach königlicher Weisung im Armeebefehl veröffentlicht werden. Für den Oberleutnant Sigmund v. Oelhafen lautete dies so:

"Nach vorläufig erlassener, jedoch fruchtlos gebliebener edictal Vorladung des im Zustande der Kriegsgefangenschaft pflichtwidrig in fremde Kriegsdienste übergetretenen Oberlieut. im 9t. L. I. Rgmt. Sigmund von Oelhafen aus Betzenstein Landgerichts Pottenstein erkennt das Generalauditoriat durch Konthumazial-Urtheil, daß der selbe aus seiner Offiziers Stelle durch einfache Entlassung aus dem Militär Verbande, und zugleich im Betretungs Falle mit einjährigem engen Festungsarrest zu bestrafen seyn. « ${ }^{95}$ Interessanterweise finden sich Urteile dieser Art weder in den armeeinternen noch in den im Regierungsblatt veröffentlichten Armeebefehlen abgedruckt ${ }^{96}$, sondern nur in den jeweiligen Personalakten. Dies gibt zur Vermutung Anlaß, daß solch ein Schandfleck im Offizierkorps entweder nicht publik gemacht oder aber dem Verurteilten die Karriere in einer anderen Armee nicht verbaut werden sollte. Vor allem letzteres findet darin seine Bestätigung, daß das Urteil gegen Oelhafen 1818 vom König gnadenhalber ausgesetzt wurde. Als mittlerweile preußischer Hauptmann beabsichtigte jener nämlich, auch weiterhin in der Armee des Königs von Preußen zu dienen. Dazu benötigte er aber einen ordentlichen Entlassungsschein aus dem bayerischen Heer und einen Vermögensnachweis ${ }^{97}$. Beides wurde ihm übermittelt und zudem der beschlagnahmte Besitz wieder freigegeben ${ }^{98}$. 
Insgesamt zeigt das Verhalten der bayerischen Behörden gegenüber den Offizieren der "Russisch-Deutschen Legion« ein etwas zwiespältiges Bild. Die individuellen Kriegsgerichtsverfahren zeugen einerseits vom Bestreben, den Charakter der bayerischen Armee als Volksheer auch beim Offizierkorps zum Ausdruck zu bringen. Die Offiziere sollten nicht mehr wie noch im 18. Jahrhundert dem Herrn dienen, der den meisten Sold bezahlte, sondern man strebte seit der Heeresreform von 1804/05 auch in Bayern ein national-patriotisches Offizierkorps an, das sich auch in Extremsituationen wie der Kriegsgefangenschaft dem Landesherrn gegenüber verpflichtet fühlen sollte ${ }^{99}$. Andererseits deuten die sehr abgeschwächt oder gar nicht vollstreckten Urteile auch darauf hin, daß Bayern gegenüber den Alliierten den eigenen Anteil an der Erhebung gegen Napoleon nicht noch nachträglich schmälern wollte, kämpften doch diese Offiziere in gewissem Sinne auch für ihr bayerisches Vaterland.

III. Die langjährigen Bemühungen Bayerns zur Klärung der Vermißtenschicksale

Durch die unvorstellbar hohen Verluste der bayerischen Armee in Rußland - am 1. Januar 1813 war das kaum ein Jahr zuvor aus über 30000 Mann bestehende Kontingent auf nur mehr 5000 Soldaten zusammengeschmolzen ${ }^{100}$ - sah sich König Max I. Joseph am 17. Januar 1813 zu dem Befehl veranlaßt, alle aus dem Feldzug zurückgekehrten Offiziere nach Gefallenen, Gefangenen und Vermißten befragen zu lassen ${ }^{101}$. Diese Aktion führte aber scheinbar zu keinem nennenswerten Ergebnis, schweigen sich doch die Quellen dazu aus. Nur Königin Karoline erhielt im Frühjahr 1813 eine Liste mit den Namen von sechs bei Vitebsk verstorbenen Offizieren ${ }^{102}$.

Dem Obersten v. Gumppenberg war neben der Repatriierung der Kriegsgefangenen auch die Klärung möglichst vieler Vermißtenschicksale auferlegt, wozu er sämtliche Heimkehrer nach verstorbenen Offizieren, nicht aber nach Mannschaften befragen ließ. Auf diese Weise kamen zwei Verzeichnisse mit den Namen von 45 bzw. 18 Offizieren sowie eine Liste mit verstorbenem Sanitätspersonal zusammen ${ }^{103}$. Eine weitere, diesmal auch auf die vermißten einfachen Soldaten ausgedehnte Vernehmung der Rückkehrer in Bayern erbrachte noch manch weiteren Todesnachweis ${ }^{104}$. Insgesamt konnten aber im Verhältnis zur großen Zahl der Vermißten nur ein Bruchteil der Schicksale geklärt werden. Von vielen Feldzugsteilnehmern fehlte auch weiterhin noch eine Lebensnachricht oder eine Bestätigung für den Tod. An den König wurde daher die Bitte herangetragen, von Staats wegen Suchanzeigen in St. Petersburger und anderen russischen Zeitungen aufgeben zu lassen - allerdings nicht aus humanitären Gründen -, sondern weil Militär- und Zivilverwaltung endlich die längst überfällige Bearbeitung von Soldzahlungen, Ordensverleihungen sowie privaten Vermögensangelegenheiten abschließen wollten. Unter Hinweis auf die noch nicht wiederhergestellten diplomatischen Beziehungen zum russischen Hof mußte dieses Gesuch allerdings vom König abgelehnt werden ${ }^{105}$.

Da man zwei Jahre nach dem Ende des Feldzugs kaum mehr brauchbare Nachrichten über noch in Rußland lebende Bayern erwartete, wurden per königlichem Reskript vom 9. April 1815 alle noch vermißten Offiziere aus den Listen der Regimenter und Bataillone gestrichen ${ }^{106}$. Trotzdem bedrängten auch weiterhin Angehörige von Vermißten den König und andere hohe Persönlichkeiten, mit Hilfe der wiedereröffneten bayerischen Gesandtschaft in St. Petersburg Nachforschungen über angeblich noch in Rußland zurückgehaltene Bayern anzustellen. In manchen, scheinbar begründeten Fällen wurden solche Schritte auch unternommen. Trotz bereitwilligster Unterstützung der russischen Behörden blieben alle Bemühungen erfolglos ${ }^{107}$ - ausgenommen im Jahre 1837. Im Zusammenhang mit der Suche nach dem Oberleutnant Christoph 
Wilhelm Birkner händigte die russische Seite ein Verzeichnis mit folgendem Titel aus: »Liste des officiers \& soldats Bavaroise qui ont été faite prisonnier de guerre \& sont séjournée à Bialistok depuis 1813 jusqu’à 1815. « $^{108}$ Bis auf 23 Personen waren alle hierin aufgeführten 239 bayerischen Kriegsgefangenen bereits 1814 Oberst v. Gumppenberg übergeben worden.

Außer Bayern standen auch andere deutsche Staaten angesichts der vielen Vermißten vor dem Problem, Verwaltungsangelegenheiten nicht erledigen zu können, zumal es auch an sicheren Todesnachweisen fehlte. Im Einverständnis mit der russischen Regierung sandte Preußen deshalb in den Jahren 1818/19 den hannoverschen Leutnant Heinrich Meyer in 36 russische Gouvernements, um bei Polizeistellen und Gerichten Nachrichten über Leben oder Tod der Verschollenen zu suchen. Zur Durchführung seines Auftrags hatte er von den preußischen Stellen eine Liste mit 16000 Vermißtennamen mitbekommen. Davon konnte er 5830 Schicksale klären. Bei 4933 Personen wies er den Tod nach, bei 702 konnte die Zugehörigkeit zur »Russisch-Deutschen Legion« nachgewiesen werden. 49 Soldaten waren aus der Kriegsgefangenschaft entlassen worden. Bei 147 stand fest, daß sie sich noch in Rußland befanden und sich teilweise dort ansässig gemacht hatten. Darüber hinaus erstellte Meyer eine Liste mit 2843 Soldaten deutsch klingenden Namens, wobei die Herkunftsländer jedoch unbekannt waren ${ }^{109}$.

Durch einen Artikel in der Augsburger Politischen Abendzeitung vom 10. Juni 1820, der einen Bericht der Allgemeinen Preußischen Staatszeitung über die Mission Leutnant Meyers zusammengefaßt wiedergab ${ }^{110}$, erfuhr das Generalkommando München von dieser Suchaktion. Ein daraufhin an den König gerichteter Vorschlag, bei diesem Offizier doch auch Erkundigungen nach den verschollenen Bayern einzuholen, wurde bereitwillig angenommen und in die Tat umgesetzt ${ }^{111}$. Am 31. Dezember 1820 erhielt die bayerische Gesandtschaft in Berlin von Meyer zwei Verzeichnisse. Das erste wies 34 Namen von Bayern auf, die als Kriegsgefangene in den russischen Untertanenverband übergetreten waren. Die zweite Liste enthielt 469 Namen von Verstorbenen, zumeist unter Angabe des Sterbeortes ${ }^{112}$. Im März 1821 stellte Meyer dem bayerischen Gesandten in Berlin, Graf Rechberg, noch einmal eine namentliche Aufstellung zu, die 2734 in Rußland zurückgebliebene Deutsche enthielt. Diese Liste war für die bayerischen Behörden insofern bedeutsam, weil davon 790 Personen 1812 zwar in französischen Diensten standen, aber aus jenen Gegenden kamen, die seit 1815 zum bayerischen Rheinkreis gehörten ${ }^{113}$. In Bayern dienten diese Verzeichnisse dann als amtliche Todesnachweise ${ }^{114}$ und den Regimentern zur Vervollständigung der Verlustlisten, die ohnehin sehr ungenau und zumeist nur summarisch waren. Als man im Zusammenhang mit der Aufstellung von Gefallenengedenktafeln 1830 daranging, die Verluste der Kriege zwischen 1805 und 1815 namentlich zu erfassen, konnten sämtliche Truppenteile der bayerischen Armee zusammen lediglich 865 Namen angeben ${ }^{115}$.

Die letzten Versuche, das Schicksal manches verschollenen bayerischen Soldaten zu klären, wurden spätestens dann gemacht, als die Bearbeitung von Erbschaftsangelegenheiten anstand. Bis über die Mitte des 19. Jahrhunderts hinaus veröffentlichten Gerichte immer wieder Aufrufe in Zeitungen, worin seit 1812 vermißte Personen mit Erbansprüchen gesucht wurden ${ }^{116}$. Inwieweit solche Annoncen Erfolg hatten, ist nicht bekannt. Höchstwahrscheinlich hat sich niemand mehr von den Gesuchten gemeldet, allenfalls vielleicht einige Betrüger ${ }^{117}$.

Herrn Dr. Rainer Braun vom Bayerischen Hauptstaatsarchiv München, Abt. IV Kriegsarchiv, bin ich für die stets freundliche und zuvorkommende Unterstützung bei der Bereitlegung der Archivalien zu großem Dank verpflichtet. 
1 Stellvertretend für die ältere, zumeist von Offizieren der bayerischen Armee im amtlichen Auftrag vorgenommene Kriegsgeschichtsforschung vgl. M. Leyh: Die Feldzüge des Königlich Bayerischen Heeres unter Max I. Joseph von 1805 bis 1815. München 1935 (= Geschichte des Bayerischen Heeres. Bd 6, 2.) Neuere Ergebnisse finden sich bei R. Braun: Die Bayern in Rußland 1812. In: Wittelsbach und Bayern. Hrsg. H. Glaser. Bd 3,1. München 1980, S. 260-271. Ders.: Der Untergang der Bayerischen Armee 1812. In: ebd., Bd 3,2, S. 273. Zur Erinnerungspflege an den russischen Feldzug in Bayern vgl. W. Schmidt: Denkmäler für die bayerischen Gefallenen des Rußlandfeldzuges von 1812. In: Zeitschrift für bayerische Landesgeschichte 49 (1986) 303-326. Siehe auch Bayern und seine Armee. Eine Ausstellung des bayerischen Hauptstaatsarchivs aus den Beständen des Kriegsarchivs (= Ausstellungskataloge der Staatlichen Archive Bayerns. Bd 21.) Hrsg. von der Generaldirektion der Staatlichen Archive Bayerns. München 1987, S. 58 f.

P. Holzhausen: Die Deutschen in Rußland 1812. Leben und Leiden der Moskauer Heerfahrt. Berlin 1912. Zur Kriegsgefangenschaft vgl. bes. S. 207-229. Allgemein zum Kriegsgefangenenrecht vgl. F. Scheidl: Die Kriegsgefangenschaft von den ältesten Zeiten bis zur Gegenwart. Eine völkerrechtliche Monographie. Berlin 1943.

3 Kurze Hinweise bei Braun (wie Anm. 1), S. 268.

4 Vgl. J. Schrafel: Merkwürdige Schicksale des ehemaligen Feldwebels Joseph S., vorzüglich im russischen Feldzuge und in der Gefangenschaft 1812-1814. Nürnberg ${ }^{2} 1835$, S. 93. Beschreibung der Schicksale und Leiden des ehemaligen Korporals B[üttner] während seiner 19monatlichen Gefangenschaft in Rußland in den Jahren 1812 und 1813. [0. O.] 1829, S. 5. F. v. Furtenbach: Krieg gegen Rußland und russische Gefangenschaft. Aufzeichnungen des Oberleutnants Friedrich von Furtenbach aus den Jahren 1812/13. Nachgesehen und eingeführt von F. v. Furtenbach. Nürnberg, Leipzig 1912, S. 99-102. L. v. Hohenhausen: Erinnerungen zu den Feldzügen 1805-1812, insbesondere zum Kriege gegen Rußland 1812; Bayerisches Hauptstaatsarchiv München, Abt. IV, Kriegsarchiv (im folgenden zit. KA), HS 702. J. Koestler: Die merkwürdigsten Jahre meines Lebens vom 15. Februar 1812 bis zum 24. April 1814. München 1814, KA, HS 703. M. v. Stubenrauch, Feldzugstagebuch für 1812-1814, KA, HS 725. J. B. Nagel: Die Tage meiner russischen Gefangenschaft 1813, Stadtarchiv Regensburg, M 316.

5 Tagebuch des Generalmajors Maximilian von Preysing-Moos, Führers der bayerischen Kavalleriedivision im Feldzuge nach Rußland 1812. In: Darstellungen aus der bayerischen Kriegs- und Heeresgeschichte 21(1912) 24-55, hier S. 54.

6 Vgl. Holzhausen (wie Anm. 2), S. 215.

7 Vgl. einen Brief des Kommandeurs der »Russisch-Deutschen Legion«, Chasot, an Frhr. vom Stein vom 11./23. 8. 1812. In: Freiherr vom Stein. Briefe und amtliche Schriften. Bd 3. Bearb. v. E. Botzenhart. Neu hrsg. von E. Hubatsch. Stuttgart 1961, Nr. 513, S. 725-728.

B Vgl. G. Venzky: Die russisch-deutsche Legion in den Jahren 1811-1815. Wiesbaden 1966 (=Veröffentlichungen des Osteuropa-Instituts München. Bd 30.), S. 73.

9 Vgl. Schrafel (wie Anm. 4), S. 93.

10 Vgl. Tagebuch (Leutnant Doepp) aus dem Feldzuge 1812. Hrsg. H. Zschokke. In: Erheiterungen. Bd 2, H. 7 und 8 (1824), S. 35-79 u. 119-167, hier S. 121.

11 Vgl. Der Feldzug von 1812. Denkwürdigkeiten eines württembergischen Offiziers. Hrsg. H. Kohl. Leipzig 1912, S. 228.

12 Vgl. Büttner (wie Anm. 4), S. 10. Furtenbach (wie Anm. 4), S. 115; Hohenhausen (wie Anm. 4).

13 Von 431 Gefangenen in der Kolonne des bayerischen Leutnants Doepp, die am 5. 11. 1812 vom Kloster Zabiali aufgebrochen waren, kamen nach einem vierwöchigen Marsch am 1. 12. nur mehr 60 bis 80 Personen am Bestimmungsort Pskov an. Der Rest war unterwegs umgekommen. Vgl. Doepp (wie Anm. 10), S. 62. Der Trupp, in dem der Aktuar Köstler vom lettischen Dünaburg (heute Daugavpils) nach Pskov marschierte, war von anfangs 300 auf 102 Gefangene zusammengeschmolzen. Pro Nacht starben sechs bis zehn Mann. Vgl. Koestler (wie Anm. 4).

$14 \mathrm{Vgl}$. Holzhausen (wie Anm. 4), S. $211 \mathrm{f}$.

$15 \mathrm{Vgl}$. Furtenbach (wie Anm. 4), S. 144. Die deutschen Truppen Napoleons wurden wegen ihrer Brutalität vom russischen Gegner als »bespardonnoje voisko« (= Heer ohne Pardon) bezeichnet. Vgl. V. Gitermann: Geschichte Rußlands. Bd 2. Hamburg 1949, S. 360.

16 Vgl. Braun (wie Anm. 1), S. 265.

$17 \mathrm{Vgl}$. Furtenbach (wie Anm. 4), S. 144

18 Vgl. A.v. Thurn und Taxis: Aus drei Feldzügen 1812 bis 1815. Erinnerungen. Leipzig 1912, S. 103. Vgl. F. Mändler: Erinnerungen aus meinen Feldzügen. Hrsg. F. Schneidawind. Nürnberg 1854, S. 87.

19 Vgl. Furtenbach (wie Anm. 4), S. $122 \mathrm{f}$.

20 Vgl. Doepp (wie Anm. 10), S. 74 f. Vgl. Nagel (wie Anm. 4).

21 Vgl. Furtenbach (wie Anm. 4), S. 163.

22 Die Errichtung eigener Kriegsgefangenenlager scheint eine englische Erfindung gewesen zu sein. Wahrscheinlich handelte es sich um das erste zu diesem Zweck erbaute Lager der Welt, das 1796 in Norman Cross eingerichtet wurde. Vgl. M. D. Howe: Das Lager für napoleonische Kriegsgefangene in Norman Cross, Huntingdonshire 1796-1816. In: Festung, Garnison, Bevölkerung. Historische Aspekte der Festungsforschung. Die Vorträge des 2. Internationalen Kolloquiums zur Fe- 
stungsforschung (29.-31. Oktober 1982). Wesel 1982 (= Schriftenreihe Festungsforschung. Bd 2.), S. $167-184$.

23 KA, B 488, "Liste des officiers \& soldats Bavaroise qui ont été faite prisonnier de guerre \& sont séjournée à Bialystok depuis 1813 jusqu'à 1815 .«

24 Vgl. Holzhausen (wie Anm. 2), S. 215.

$25 \mathrm{KA}, \mathrm{B} 504 . \mathrm{Vgl}$. Stubenrauch (wie Anm. 4). Vgl. Doepp (wie Anm. 10), S. 139. Vgl. Furtenbach (wie Anm. 4), S. 180. Vgl. A. v. Harold: Erinnerungen an den Ausmarsch nach Rußland 1812 und die russische Gefangenschaft 1812-1814, KA, HS 699.

26 Vgl. Furtenbach (wie Anm. 4), S. 134. Vgl. Hohenhausen (wie Anm. 4). Vgl. Stubenrauch (wie Anm. 4). Vgl. Koestler (wie Anm. 4).

27 Vgl. Tagebuch des Militär-Unterapothekers Grasmann. Feldzug 1812, KA, HS 693. Vgl. auch Th. Kraus: Geschichte der bayerischen Heeresabtheilung im Feldzuge gegen Rußland 1812. Augsburg 1857, S. 231. Im Lazarett von Polock war der bayerische Feldspitalarzt Dr. Samiller zusammen mit 14 Chirurgischen Praktikanten und einem Militärapotheker zum Dienst eingeteilt.

28 Vgl. Doepp (wie Anm. 10), S. 55. Vgl. Schrafel (wie Anm. 4), S. 119.

29 Vgl. Preysing (wie Anm. 5), S. 55. Vgl. Doepp (wie Anm. 10), S. 69. Vgl. Schrafel (wie Anm. 4), S. 115 u. 159. Vgl. Büttner (wie Anm. 4), S. 117. Vgl. Nagel (wie Anm. 4). Vgl. Grasmann (wie Anm. 27).

$30 \mathrm{Vgl}$. Furtenbach (wie Anm. 4), S. 182. Von ähnlich günstigen Lebensmittelpreisen berichtet auch der Oberleutnant Johann Baptist Nagel aus Cernikov und Pensa. Vgl. Nagel (wie Anm. 4).

31 Vgl. Doepp (wie Anm. 10), S. 130 f.

32 Der bayerische Sergeant Schrafel arbeitete freiwillig bei einem Apotheker. Zusammen mit der behördlichen Löhnung standen ihm damit täglich $131 / 2$ Kreuzer zur Verfügung, ein seinem Eindruck nach hohes Einkommen in Rußland. Vgl. Schrafel (wie Anm. 4), S. 161.

33 Bayerisches Hauptstaatsarchiv München, Abt. III, Geheimes Hausarchiv (im folgenden zit. GH), Nachlaß Adalbert, Nr. 232, Brief Königin Karolines von Bayern an ihre Mutter vom 17. 1. 1813.

$34 \mathrm{GH}$, Nachlaß Adalbert Nr. 233, Brief vom 20. 1. 1813. Vgl. auch A. Prinz von Bayern: Max I. Joseph von Bayern. Pfalzgraf, Kurfürst und König. München 1957, S. 627.

$35 \mathrm{GH}, \mathrm{Nachlaß}$ Adalbert, Nr. 243, Brief Königin Karolines von Bayern an ihre Mutter vom 31. 1. 1813. Vgl. auch L. v. Seiboldsdorf: Das kgl. baier. Armee Corps in dem Feldzuge gegen Rußland im Jahre 1812, KA, HS 723.

$36 \mathrm{KA}, \mathrm{B} 488$, Billet vom 22. 9. 1813.

37 KA, B 489, Schreiben der Militärhauptkasse an Prinzessin Amalie von Baden vom 14. 4. 1813. Auch das badische Kriegsministerium ließ zur Unterstützung seiner in Rußland gefangenen Offiziere 10000 Gulden an die russischen Behörden überweisen. Vgl. Denkwürdigkeiten des Markgrafen Wilhelm von Baden. Bd 1: 1792-1818. Hrsg. von der Badischen Historischen Kommission. Bearb. von K. Obser. Heidelberg 1901, S. 213.

38 Ebd., Marginalie Kriegsministers v. Triva auf einer Anweisung des Kriegsministeriums an die Militärhauptkasse vom April 1813.

$39 \mathrm{KA}, \mathrm{B} 430$ a, Quittungsverzeichnis von Oberst Comeau vom 19. 1. 1814.

40 Ebd., Berechnung des Gagenguthabens von Oberleutnant Schnittling vom 13. 4. 1814.

41 KA, B 489.

42 Vgl. Furtenbach (wie Anm. 4), S. 183. Vgl. Nagel (wie Anm. 4).

43 Wie Anm. 39.

$44 \mathrm{KA}, \mathrm{B} 489$.

$45 \mathrm{KA}, \mathrm{B} 430$ a, Brief Prinzessin Amalie von Badens vom 15. 4. 1815.

46 Vgl. Doepp (wie Anm. 10), S. 150. Vgl. Koestler (wie Anm. 4). Vgl. Hohenhausen (wie Anm. 4) Vgl. Harold (wie Anm. 25). Vgl. Furtenbach (wie Anm. 4), S. 185-187. Der bayerische Oberleutnant Nagel unterrichtete beispielsweise die Tochter des Gouverneurs von Cernikov im Zeichnen. Vgl. Nagel (wie Anm. 4). In den Aufzeichnungen des späteren Generalmajors v. Harold hat sich neben Zeichnungen russischer Orte und Einladungskarten russischer Adeliger zum Tee oder Billardspiel auch der Haarzopf einer Nedešda Šedrinskij erhalten, zu der er offensichtlich eine sehr enge Beziehung hatte. Vgl. Bayern und seine Armee (wie Anm. 1), S. 59 ff.

47 Zum Frontwechsel Bayerns im Jahre 1813 vgl. E. Weis: Bayern im napoleonischen Kontinentalsystem. In: M. Spindler (Hrsg.): Handbuch der bayerischen Geschichte. Bd 4,1: Das neue Bayern 1800-1970. München 1974/75, S. 34-38.

48 $\mathrm{Vgl}$. "Instruction pour le général major baron de Verger se rendant au quartier général des puissances alliés«. Abgedr. in: M. Doeberl: Bayern und die deutsche Erhebung gegen Napoleon. Abhandlungen der Historischen Klasse der K. B. Akademie der Wissenschaften 24 (1907) 347-432, hier S. 431. Zum Schicksal des bereits 1811 auf Befehl Napoleons nach Danzig entsandten 13. bayer. Infanterieregiments vgl. F. Schubert/H. Vara: Geschichte des Königlich Bayerischen 13. Infanterieregiments. Bd 1. München 1906. Zur Verteidigung der Festung Thorn an der Weichsel durch bayerische Truppen vgl. R. v. Hößlin/E. Hagen: Die Verteidigung von Thorn vom 20. Januar bis 16. April 1813. In: Darstellungen aus der bayerischen Kriegs- und Heeresgeschichte 3(1894) 27-64.

49 KA, B 488.

50 KA, B 504, Schreiben Nesselrodes an Verger vom 27. 11. 1813.

51 KA, B 488, Schreiben des Kriegsministeriums an Verger vom 8. 12.1813. 
52 KA, B 504, Schreiben Vergers an das Kriegsministerium vom 27. 12. 1813.

53 Vgl. Büttner (wie Anm. 4), S. 49-54. Vgl. Schrafel (wie Anm. 4), S. 170. Vgl. Hohenhausen (wie Anm. 4). Vgl. Nagel (wie Anm. 4).

54 Vgl. Furtenbach (wie Anm. 4), S. 191. Der Sergeant Schrafel erinnerte sich später, daß jeder Bayer ein Hemd, Pantalons, Stiefel, Strümpfe oder wollene Lappen, einen Pelz, eine Mütze und einen Mantel erhalten habe. Vgl. Schrafel (wie Anm. 4), S. 170. Nach den Memoiren des Oberleutnants Nagel waren zur Einkleidung jedes bayerischen Offiziers 100 Rubel vorgesehen. Vgl. Nagel (wie Anm. 4).

55 Vgl. Harold (wie Anm. 25). Vgl. Grasmann (wie Anm. 27). Vgl. Koestler (wie Anm. 4). Vgl. Stubenrauch (wie Anm. 4). Vgl. Büttner (wie Anm 4), S. 51. Vgl. Schrafel (wie Anm. 4), S. 170. Vgl. Doepp (wie Anm. 10), S. 159.

$56 \mathrm{Vgl}$. Furtenbach (wie Anm. 4), S. 193.

$57 \mathrm{KA}, \mathrm{B} 504$, Instruktion des Kriegsministeriums an Oberst von Gumppenberg vom 6. 1. 1814.

58 Ebd., Bericht Gumppenbergs an das Kriegsministerium vom 7. 2. 1814.

$59 \mathrm{Vgl}$. Furtenbach (wie Anm. 4), S. 217. Vgl. Stubenrauch (wie Anm. 4).

$60 \mathrm{KA}, \mathrm{B} 504$, Bericht Gumppenbergs an das Kriegsministerium vom 22. 1. 1814.

61 Gumppenberg beklagte insbesondere den jammervollen Zustand der aus preußischem Gewahrsam überstellten Gefangenen, die im Gegensatz zu denen aus dem russischen Gebiet mit fast nichts auf dem Leib in Warschau ankamen, KA, B 504, Bericht Gumppenbergs an das Kriegsministerium vom 20. 3,1814

62 Oberleutnant Furtenbach erhielt beispielsweise 43 Golddukaten. Vgl. Furtenbach (wie Anm. 4), S. 197.

63 KA, B 504, Bericht Gumppenbergs an das Kriegsministerium vom 20. 3. 1814 u. Anweisung des Kriegsministeriums an Gumppenberg vom 7. 4. 1814. Vgl. auch Harold (wie Anm. 25), der einen vom Gouverneur des Großherzogtums Warschau, Graf Lanskoji, ausgefertigten Paß nach Hause mitgebracht hatte.

64 Vgl. Furtenbach (wie Anm. 4), S. 231. Vgl. Harold (wie Anm. 25). Vgl. Stubenrauch (wie Anm. 4).

65 Vgl. Schrafel (wie Anm. 4), S. 176 f.

$66 \mathrm{KA}, \mathrm{B} 504$, Bericht Gumppenbergs an das Kriegsministerium vom 2. 3. 1814. Ein Quart entsprach in Bayern etwa 0,267, in Preußen dagegen 1,145 Liter. Vgl. Meyers Enzyklopädisches Lexikon in 25 Bänden. Bd 19. Mannheim 1977, S. 465.

67 KA, B 504 (wie Anm. 66), 23 Rapporte der Kommandantschaft Bayreuth an das Generalkommando Nürnberg zwischen dem 31. 3. und 27. 12.1814.

68 Ebd., Hauptbericht Gumppenbergs an das Kriegsministerium vom 30. 7. 1814.

69 KA, B 430 a, Schreiben Prendels an den bayerischen König vom 15./27. 12. 1813. Schreiben des Kriegsministeriums an Prendel vom 24. 3. 1814. Schreiben Prendels an das Kriegsministerium vom 2./14. 4. und 1./13. 10. 1814 .

70 KA, B 504, Note des Außenministers an das Kriegsministerium vom 24. 11. 1814. Der bayerische Gesandte Graf de Bray hatte zwei heimkehrende Offiziere mit 75 bzw. 50 Gulden unterstützt.

7t Ebd., Note des preußischen Grafen Bruges an den bayerischen Gesandten in Berlin vom 1. 9. 1816. Notenwechsel zwischen dem bayerischen Außenministerium und Kriegsministerium vom 11. u. 18. 10. 1816. Zusammen mit französischen Kriegsgefangenen wurden im August 1816 acht bayerische Soldaten den preußischen Behörden in Danzig übergeben.

72 KA, B 430 a, Schreiben des bayerischen Agenten Gaddum in Triest an das Kriegsministerium vom 6. 4. 1815. Mehrere Bayern kamen in Frühjahr 1815 zusammen mit italienischen Kriegsgefangenen aus Rußland nach Triest.

3 Allgemein zur "Russisch-Deutschen Legion« vgl. Venzky (wie Anm. 8). Wie ein an die portugiesischen Truppen der »Grande Armée« gerichteter Aufruf zeigt, war parallel zur "RussischDeutschen Legion« auch eine "Spanische Legion« geplant, die von Odessa aus nach Spanien geschickt werden sollte, um dort in den Kampf gegen Napoleon einzugreifen. Vgl. Vnešnjaja Politika XIX i nacala XX veka. Dokumenty rossijskogo ministerstva innostrannych del serija 1 t.6. Moskva 1962 (dt. Außenpolitik des 19. und 20. Jahrhunderts. Dokumente des russischen Außenministeriums), S. 771, Anm. 595. Vgl. auch E. Völkl: Die russische Atlantikpolitik unter Alexander I. (1801-1814). In: Saeculum 21 (1970) 41-56, hier S. 51.

74 Vgl. Seiboldsdorf (wie Anm. 35).

75 Vgl. Königsberger Zeitung Nr. 31, 13. 3. 1813, S. 309 f.

76 Vgl. Venzky (wie Anm. 8), S. 70.

$\pi$ Vgl. Büttner (wie Anm. 4), S. 6. Vgl. Schrafel (wie Anm. 4), S. 167. Der aus russischer Kriegsgefangenschaft zurückgekehrte bayerische Leutnant Reinhard gab am 31.5.1814 dem Auditor seines Regiments zu Protokoll, daß in Königsberg auf Befehl des russischen Gouverneurs Graf Sievers viele Gefangene ohne Wasser und Lebensmittel in eine kalte Kirche gesperrt worden seien, um sie gefügiger zu machen. Den gefangenen Offizieren gegenüber gab sich Sievers zunächst etwas konzilianter, indem er allen beim Eintritt in die Legion ein Handgeld von 500 Rubel in Aussicht stellte. Im Weigerungsfalle sollten die Offiziere zwar nicht dem Hungertod preisgegeben werden, jedoch drohte man mit der unverzüglichen Deportation nach Sibirien, KA, OP 80224. 
79 KA, B 488, Bericht General Delamottes an General Wrede vom 7. 9. 1814. Außer in die "RussischDeutsche Legion « waren im Laufe des Jahres 1813 auch Bayern in das preußische "Lützow-Korps" eingetreten. Im Juni 1815 gelang es den bayerischen Stellen erst nach massivem Druck beim Oberkommandierenden Blücher, einen bayerischen Unteroffizier und 43 Soldaten von diesem Verband zu übernehmen, KA, B 488, Rapport des Oberleutnants von Thurn und Taxis vom 12. und 15.6. 1815. Der namentlich bekannte bayerische Sergeant Seckenreiter wurde seinen Angaben zufolge während des Rußlandfeldzugs in ein österreichisches Ulanenregiment gepreßt, KA, B 488, Schreiben des Reservebataillons des 7. bayer. Infanterieregiments an das Generalkommando Augsburg vom 15. 11. 1815.

Bo KA, B 488, Vernehmungsprotokoll vorn 27. 8. 1814.

s1 Finanzielle Probleme führten die "Russisch-Deutsche Legion* 1813 in hannoverschen bzw. englischen Sold. Am 2.6. 1817 schlossen die Souveräne Englands, Preußens und Rußlands einen Vertrag, wodurch die Legion unter preußisches Kommando kam. In der Folgezeit wurde der Verband stark verkleinert und bildete später den Stamm für die preußischen Infanterieregimenter Nr. 30 und 31 sowie für das Ulanenregiment Nr. 8. Vgl. Venzky (wie Anm. 8), S. 109-112.

22 KA, B 499, Notenwechsel zwischen dem Außenministerium und dem Kriegsministerium vom 5. u. 8. 4. sowie vom 2. 5. 1813 .

B3 KA, B 488, Anweisung des Kriegsministeriums an Verger vom 10. 2. 1814.

B4 Ebd., Rapport Horns vom 31. 8.1814.

85 KA, B 488. Die zurückgeführten Soldaten wurden bei den Regimentern lediglich nach ihrem Werdegang in der Legion sowie nach dort dienenden bayerischen Offizieren befragt.

86 Brief Steins an Hardenberg vom 23. 5. 1814, in: Freiherr vom Stein (wie Anm. 7), Bd 4. Stuttgart 1963, Nr. 1266, S. 815 f.

87 KA, B 488, Königliches Reskript vom 23. 9. 1814. Als oberste Militärjustizbehörde war für die Kriegsgerichtsverfahren das Generalauditoriat in München zuständig. Vgl. G. Heyl: Bayerische Militärgerichte 1806 bis 1919. In: Archivalische Zeitschrift 75 (1979) 61-73.

88 Vgl. Königlich bayerisches Regierungsblatt 1813, Sp. 1052.

89 KA, OP 80 224, Protokoll des Kriegsgerichts vom 8.3. 1815. Wie aus einer Mitteilung General Wredes an das Kriegsministerium vom 7. 12. 1814 hervorgeht, war der König schon vor der Anklageeröffnung bereit gewesen, Merkel seinen Eintritt in die Legion gnadenhalber zu verzeihen.

90 KA, B 499, Kriegsgerichtsurteil vom 27. 7. 1815.

$91 \mathrm{KA}$, OP 76 576, Schreiben des Generalauditoriats an den König vom 30.08. 1814. Königliches Reskript vom 19.9.1814.

92 Ebd., Armeebefehl vom 22. 2. 1815.

93 Vgl. Regierungsblatt für das Königreich Bayern 1813, Sp. 281, Armeebefehl vom 30. 3. 1838.

$94 \mathrm{KA}$, OP 76 576, Schreiben des Außenministeriums an das Kriegsministerium vom 16. 4. 1831

95 KA, B 499, Königliches Reskript an das Generalauditoriat vom 25. 4. 1815.

$96 \mathrm{KA}, \mathrm{V} 1 / 12$, Armeebefehle vom Jahre 1815. Vgl. auch Königlich bayerisches Regierungsblatt 1815 , Sp. 545-584, 589-598, 857-876, 884-899, Armeebefehle vom 3.6., 24.6., 25.6., 30.9. und 16. 10.1815.

97 KA, B 499, Schreiben des Außenministeriums an das Kriegsministerium vom 1. 2. 1818.

98 Ebd., Königliches Reskript an das Generalauditoriat vom 12. 4. 1818. Anweisung des Innenministeriums an die Regierung des Regenkreises vom 16. 3. 1818.

99 Vgl. E. Frauenholz: Der Übergang vom Söldnertum zum Volksheer unter dem ersten bayerischen Kriegsminister von Triva. In: Zeitschrift für bayerische Landesgeschichte 9(1932) 47-53.

100 Zum exakten Personalstand des bayerischen Rußlandkontingents vgl. Braun (wie Anm. 1), S. 261 u. 269. Im Laufe des Jahres 1812 waren 35799 Bayern nach Rußland gezogen.

$101 \mathrm{KA}, \mathrm{B} 504$.

$102 \mathrm{GH}$, Nachlaß Adalbert Nr. 238, Brief Königin Karolines von Bayern an ihre Mutter vom 1. 5. 1813.

$103 \mathrm{KA}, \mathrm{B}$ 504, Verstorbenenverzeichnisse vom 2. und 20. 3. 1814.

104 Der bayerische Leutnant Strobel konnte beispielsweise bei seiner Vernehmung am 22. 4. 1814 die Namen von 100 während der Kriegsgefangenschaft verstorbener Offiziere, Unteroffiziere und Mannschaften angeben. In ganz seltenen Fällen wurden auch in der Gefangenschaft ausgestellte Totenscheine nach der Rückkehr vorgelegt, KA, B 498. Ein im April 1814 zusammengestelltes "Verzeichnis der nach den Angaben des Feld-Spitalarztes Dr. Samiller in Polock verstorbenen Militär-Individuen« enthält 22 Namen bayerischer Sanitätsdienstgrade, KA, A I 6.

105 KA, B 498, Schreiben des Königs an General Wrede vom 19. 5. 1815.

106 Ebd.

107 So zum Beispiel 1816/17 die Suche nach dem verschollenen Major v. Schleich, KA, B 504, Anweisung des Außenministeriums an die Gesandtschaft in St. Petersburg vom 21.6.1816. Schreiben der Gesandtschaft an den König vom 8. 2.1817.

$108 \mathrm{KA}, \mathrm{B} 488$.

$109 \mathrm{Vgl}$. Allgemeine Preußische Staatszeitung Berlin vom 16. 5. 1820. Meyer stellte eine erste Liste am 30. 9./12. 10. 1818 in Kamenenc-Podolsk zusammen. Darin sind vor allem im westlichen Teil Rußlands verschollene Soldaten enthalten. Ein zweites Verzeichnis sowie einen Nachtrag mit Angaben über Vermißte im östlichen europäischen Rußland und Hinweise auf Eintritte in die "RussischDeutsche Legion« sowie freiwillig in Rußland gebliebene fertigte er im Juli 1819 in St. Petersburg 
an. Vgl. F. Overkott: In Rußland Vermißte aus Rheinland und Westfalen nebst angrenzender Gebiete in Napoleons »Großer Armee« 1812-1813. Neustadt/Aisch 1963 (= Bergische Forschungen. Bd 5.), S. 5.

110 Vgl. Augsburger Politische Abendzeitung Nr. 5, 10.6.1820.

111 KA, B 504, Schreiben des Generalkommandos München an den König vom 13.6. 1820. Anweisung des Außenministeriums an die bayerische Gesandtschaft in Berlin vom 14. 8. 1820.

112 Einer dieser in den russischen Untertanenverband übergetretenen Bayern, der Junker Franz Trakkert, tauchte 1822 wieder auf, als er beim bayerischen König um einen Abschied aus dem Militärdienst nachsuchte, um in seine Heimat zurückkehren zu können. Trotz mancher Bitten der Angehörigen wurde das Gesuch zunächst mit der Begründung abgelehnt, Trackert hätte durch seine Ansässigmachung in Rußland die militärischen Dienstpflichten verletzt. Nicht zuletzt durch die Intervention Feldmarschall Wredes beim König, der auf die Jugend des damaligen Junkers (16 Jahre) und die Gnadenakte gegenüber den Offizieren der »Russisch-Deutschen Legion " hinwies, erhielt Trackert den erbetenen Abschied, KA, B 488. Zum zweiten Verzeichnis Meyers vgl. KA, B 504, Schreiben des preußischen Außenministeriums an die bayerische Gesandtschaft in Berlin vom 14. 8. 1820.

113 KA, B 504, Schreiben der bayerischen Gesandtschaft in Berlin an den König vom 20. 3. 1823.

114 In den westfälischen Provinzen Preußens reichten die Meyerschen Verzeichnisse nicht für die abschließende Bearbeitung von Verwaltungsangelegenheiten aus. Da sie keine Geburtsdaten enthielten, wurden ihre Angaben als nicht genügend für Todesbescheinigungen erachtet. Erst durch ein Gesetz vom 22. 5.1822 über »Todeserklärungen der Vermißten zwischen 1806 und 1815 erreichten die Listen volle Beweiskraft. Vgl. Overkott (wie Anm. 109), S. 6.

115 KA, B 403, namentliche Verlustlisten der Regimenter, erstellt zwischen September und November 1830. Zu diesem Gedenktafelprojekt vgl. Schmidt (wie Anm. 1), S. 318-322.

$116 \mathrm{Vgl}$. „Ediktal-Citation für Erbschaftsansprüche des Fürstlich-Öttingen-Wallersteinschen Herrschaftsgerichts Kummer«, worin man 13 verschollene Soldaten zu finden versuchte. Über zwei Jahre hinweg wurde dieser Aufruf in mehreren, auch überregionalen Blättern abgedruckt. Wochenblatt für das Fürstentum Oettingen-Wallerstein und Umgebung Nr. 16, 24. 2. 1844; Nr. 8, 22. 2. 1845; Nr. 25, 19. 4. 1845; Nr. 29, 14.6. 1845. Beilage zu Nr. 16 der Allgemeinen Zeitung, 25.2. 1845. Wochenblatt der Stadt Nördlingen Nr. 17, 29. 4. 1845; Nr. 28, 8. 7. 1845. Beilage zu Nr. 153 des Korrespondenten von und für Deutschland, 2. 6. 1845. Augsburger Abendzeitung Nr. 54, 29. 5. 1845.

117 So versuchte schon im Jahre 1818 ein Michael Wohlleben als angeblich noch in Rußland zurückgehaltener bayerischer Soldat 100 Gulden von den Behörden zu erschleichen, mit der Vorgabe, nur so nach Bayern zurückkehren zu können, KA, B 504. Mit einer rührseligen Geschichte über sein Schicksal als Spätheimkehrer in einer Zeitung glaubte ein Georg Rauch, alias der gerichtsbekannte Betrüger Johann Guth, hilfsbereite Bürger um eine Spende prellen zu können Als der Sachverhalt von der Polizei untersucht wurde, stellten sich sämtliche Angaben als Schwindel heraus. Georg Rauch wurde daraufhin auf unbestimmte Zeit in die Zwangsarbeitshausanstalt Plassenburg bei Kulmbach eingeliefert. Vgl. Die Bayer'sche Landbötin Nr. 144, 1. 12. 1832, S. 1160 . Das Urteil gegen Rauch wurde veröffentlicht in: Der bayerische Volksfreund Nr. 78, 15. 5. 1834, S. 632. 
